\section{THE ALLEGED IMPROVED SPECULUM RECTI.}

\section{To the Editor of The Lavoet.}

Srr,-I beg your insertion of these few lines in relation to the speculum ani, of late so much the subject of medical conversation.

I do not trouble you respecting the originality of the invention of the instrument by Mr. Salmon many years since,-that having been fully proved in the letter to your journal some months bask by Dr. Roberts, formerly house-surgeon to this charity,- - but in consequence of a second piracy, as to a moveable handle, reported in your columns of the 29 th November, which handle, I feel it is my duty to inform you, is a part of the original instrument used here, as witnessed by numerous members of the profession.

I am, Sir, your obedient servant,

Henry R. Burton, House Surgeon to the Fistula Infirmary.

\section{To the Editor of The Lanoer.}

Str,-Having been in the habit of taking in your valuable periodical for many years, and perceiving in your publication of November the $29 \mathrm{th}$ ult., a drawing of a speculum for the rectum, together with an assumed original improvement of a moveable handle, we deam it justice to ourselves, as well as to Mr. Salmon, to state that in the course of business we made, at the instructions of that gentleman, a similar instrument, with and without a moveable handle, more than ten years since.

Relying on your sense of justice for the insertion of this letter,

We are, Sir, your obedient servants,

Evans \& Co.

Old Change, St. Paul's, Dec. 1851. Surgical Instrument Makers.

\section{THE LATE MEETING AT ROSS. To the Editor of The LaveEt.}

SIR,-With reference to Mr. Arthur Armitage's letter in The LANCET of December 13th, about the Ross Dispensary meeting, allow me to say that it was his futher, Mr. Whaley Armitage, who spoke at the meeting of governors. Mr. Armitage has been steward of the Guy's Hospital property, near Ross, for a very long period, and a year or two ago, he astonished the neighbourhood by informing them that he had resigned, and that his son was appointed to his situation. This smuggling-in of the son was managed in capital style, worthy of the best days of jobbing.

Mr. Armitage, Sen., still, I believe, has a retiring salary, probably paid by the son, during his life. But the main fact is, that the speech censured by you was made by one who for very many years drew all his income (and a good one, too) from an allopathic hospital, and who even now, if not directly, at least indirectly, in his son, continues to live upon the hospital. If the January meeting resolve to keep globules at the dispensary, we will see how Mr. Arthur Armitage will vote; and if he has no vote at present, he should, in common gratitude to Guy's Hospital for the coat he wears and the bread he eats, qualify himself to vote against homceopathy at the Ross Dispensary.

A certain number of dispensary letters used to be, and, I doubt not, still are, signed by the steward for the governors of Guy's Hospital, their subscription entitling them to so many recommendatory letters; and it will be curious if their steward sends, or allows, a patient to attend a homcopathic physician recommended through the charity of the Guy's Hospital governors.

December, 1851 . Your obedient servant,

\section{ORIGINAL EXPERIMENT ON THE SOUNDS OF THE HEART. \\ To the Editor of The LANCET.}

Sir,-I send you a short notice $c f$ an experiment $I$ have performed, with the assistance of my fellow-students, with a view to determine the cause of the first sound of the heart.

Chloroform having been administered to a large dog, and insensibility produced, an opening was made into the trachea, and the exterior part of the thorax removed. Artificial respiration being kept up, the heart was seen contracting and dilating. The pericardium was now slit up, and the sounds, which were heard through the medium of a stethoscope, were louder and more distinct than before the operation. The superior and inferior vena cava, and the pulmonary veins at their entrance to the left auricle, were now tightly compressed between the fingers, and the heart continuing its action, a stethoscope was again applied, and neither first nor second sound was heard. After a short interval the veins were allowed to pour their contents into both sides of the heart, and both sounds were instantly reproduced. The veins were again compressed, and all sound extinguished, notwithstanding the heart contracted vigorously. Blood was again let in, and both sounds were restored.

This experiment was performed on the 1st of this month, and successfully repeated on the 10 th, on which occasion the heart's action was kept up for forty minutes, and the facts as stated above severally attested by $\mathrm{my}$ respected anatomical teachers, and a number of fellow-students.

As I am still engaged upon the subject, I hope shortly to send you further particulars, with full acknowledgments of the great assistance and encouragement $I$ have received from those around me.

I have the honour to remain, Sir, your obedient servant, George Britton Halford. st. George's School of Anatomy, Grosvenor-place.

P. S.--Should any one be induced to try the experiment before my next communication, great advantage will be obtained by using a small pair of Liston's bull-dog forceps to compress the inferior vena cava.

\section{ENGLISH PHYSICIANS IN FRANCE. To the Editor of The LaNoET.}

SrR,-In the month of July last you were so good as to publish a letter of mine, giving some explanations as to a petition I had presented to the Assemblée Nationale, requesting permission to practise amongst my countrymen, and $I$ then mentioned that a Committee had been appointed to investigate my claim.

The Parliament rose early in August, but the different Comnittees continued to sit for some time after. On the 14 th of that month, the Chairman formally wrote to me to say that the Committee on my petition had decided favourably; and I heard through a private source, on which reliance was to be placed, that they were unanimous in their decision.

My intention was not to have troubled you again till the final settlement of matters. Recent events, however, have altered everything, and I must, therefore, trust in your indulgence for the present intrusion.

I have the bonour to be, your obedient servant,

Paris, December, 1851 . James Moffatr, M.D.

\section{UNIVERSAL VACCINATION, AND THE VACCI. NATION ACT. \\ To the Editor of THE LANCET.}

Srr,-In one of your leaders of the 29th ult., referring to the proceedings of the Epidemiological Society, you point out the importance of the following question to members of the profession generally:-

"Can you suggest any plan for insuring the vaccination of every person throughout the kingdom?"

Without at present noticing in what way this end may be effectually attained, I wish to point out in what way it is most effectually retarded, - and that is, by the operation of the Vaccination Act itself.

Instead of all duly qualified practitioners being allowed to vaccinate with the understanding and order that it is done by themselves, and not by proxy, and the vouchers afterwards forwarded to the propor source for payment; the privilege is, as you are aware, in the majority of cases, limited to the regularly appointed officers of the poor-law staff.

The following are the consequences, for which $I$ can answer fram experience and observation:- -

1st. Advantage has been taken of this privilege by young men newly appointed, to deluge their own and others' districts with disreputable placards, stating what is, in fact, false-viz., that on certain days, at certain hours, the public may be by them vaccinated gratis. In large towns and dense districts, there is a large class far removed from the necessity of parochial relief, and the private patients of other men, who either wait the opportunity of gratuitous vaccination, or expect their own surgeon to do it for nothing, or next to nothing.

Indly. In provincial districts it often happens that there is a surgeon resident in a village forming part of a district in another man's contract, and in such districts, after small-pox is established as an epidemic, then comes a notice left at the post-office, stating that on such and such days the parish surgeon will attend to vaccinate gratis (again), not only his 